\title{
Significance of Cold Renal Perfusion on Renal Function and Clinical Outcomes When Renal Ischemia Time Exceeded 30 Min during Pararenal and Juxtarenal Abdominal Aortic Aneurysm Surgery
}

\author{
Koji Furukawa*, Kosuke Mori, Yukie Shirasaki, Hirohito Ishii, Kunihide Nakamura \\ Department of Cardiovascular Surgery, Faculty of Medicine, University of Miyazaki, Miyazaki, Japan \\ Email: *koji_furukawa@med.miyazaki-u.ac.jp
}

How to cite this paper: Furukawa, K., Mori, K., Shirasaki, Y., Ishii, H. and Nakamura, K. (2019) Significance of Cold Renal Perfusion on Renal Function and Clinical Outcomes When Renal Ischemia Time Exceeded 30 Min during Pararenal and Juxtarenal Abdominal Aortic Aneurysm Surgery. World Journal of Cardiovascular Surgery, 9, 97-107.

https://doi.org/10.4236/wjcs.2019.99012

Received: July 24, 2019

Accepted: September 3, 2019

Published: September 6, 2019

Copyright $\odot 2019$ by author(s) and Scientific Research Publishing Inc. This work is licensed under the Creative Commons Attribution International License (CC BY 4.0).

http://creativecommons.org/licenses/by/4.0/

\section{(c) (i) Open Access}

\begin{abstract}
Objectives: To investigate the influence of cold renal perfusion on renal function and clinical outcomes in cases where the renal ischemia time exceeded 30 min during pararenal and juxtarenal abdominal aortic aneurysm (P/JAAA) surgery. Methods and Results: Fifty-four patients who underwent open repair for P/JAAAs were retrospectively analyzed. Thirty-nine patients received renal perfusion with cold Ringer's solution (perfusion group) and 15 patients did not receive renal perfusion (non-perfusion group). There were no significant differences in preoperative serum creatinine level $(\mathrm{Cr})(1.08 \pm$ 0.42 vs. $1.35 \pm 0.71 \mathrm{mg} / \mathrm{dL}, \mathrm{p}=0.09)$, percentage of patients with $\mathrm{Cr}>2$ $\mathrm{mg} / \mathrm{dL}[2 / 38(5 \%)$ vs. $2 / 15(13 \%), \mathrm{p}=0.8]$, and renal ischemia time during proximal aortic clamping $(49 \pm 21$ vs. $47 \pm 11 \mathrm{~min} ; \mathrm{p}=0.8)$ between the groups. Postoperative $\mathrm{Cr}$ was significantly lower in the perfusion group than in the non-perfusion group $(1.48 \pm 0.76$ vs. $2.23 \pm 1.21 \mathrm{mg} / \mathrm{dL}, \mathrm{p}<0.01)$. The percentage of patients with postoperative $\mathrm{Cr}>2 \mathrm{mg} / \mathrm{dL}$ was also significantly lower in the perfusion group than in the non-perfusion group [5 (13\%) vs. 7 $(47 \%), \mathrm{p}<0.01)]$. At discharge, $\mathrm{Cr}$ returned to preoperative levels in both groups. All patients were discharged from the hospital without incidents. Conclusion: Renal artery perfusion with cold Ringer's solution clearly reduced the deterioration of postoperative renal function compared to non-renal perfusion.
\end{abstract}

\section{Keywords}

Cold Renal Perfusion, Pararenal Abdominal Aortic Aneurysm, Juxtarenal 
Abdominal Aortic Aneurysm, Suprarenal Clamping, Renal Function

\section{Introduction}

Although abdominal aortic aneurysms (AAAs) are increasingly treated by endovascular aortic repair (EVAR), pararenal and juxtarenal AAAs (P/JAAAs) represent a growing number of conditions requiring open repair [1] [2]. Surgical treatment of P/JAAAs requires suprarenal aortic cross-clamping, causing temporary renal artery occlusion. Suprarenal clamping is associated with frequent renal impairment and higher mortality and morbidity rates [1]-[6].

The risk of postoperative renal failure increases with longer durations of suprarenal clamping, especially when the ischemia period exceeds $30-45 \mathrm{~min}$ [1] [7] [8]. To preserve renal function, cold renal perfusion during suprarenal clamping has been performed. However, it was performed mostly in selected patients with preoperative renal insufficiency or when longer renal ischemia was anticipated; none of the studies compared the effects of cold renal perfusion with a control group. Thus, its efficacy has not been definitively determined [9].

We have used cold renal perfusion to preserve renal function for P/JAAAs requiring suprarenal aortic cross-clamping in principle. This study aimed to analyze our surgical experiences for P/JAAAs and to investigate the influence of cold renal perfusion on renal function and clinical outcomes by comparing patients with or without cold renal perfusion.

\section{Materials and Methods}

\subsection{Patients}

In our facility, open repair was standard for P/JAAAs requiring suprarenal clamping and 61 patients underwent open repair for P/JAAAs between January 2001 and December 2018. Among them, 54 patients were retrospectively analyzed, excluding 3 patients who were dependent on hemodialysis for end-stage renal disease and 4 patients whose renal ischemia time was less than $30 \mathrm{~min}$. Thirty-nine patients who received renal perfusion with cold Ringer's solution comprised the perfusion group, and 15 patients who did not receive renal perfusion comprised the non-perfusion group.

Juxtarenal AAA is defined as an aneurysm that necessitates suprarenal or inter-renal proximal clamping for open surgery with infrarenal reconstruction. Likewise, pararenal AAA (PAAA) also necessitates suprarenal, and sometimes supraceliac clamping, but requires additional revascularization of the renal artery [10].

The Institutional Review Board of Miyazaki University Hospital approved this study and waived the requirement for informed consent for participation on account of the retrospective nature of the study. General informed consent for undergoing the recommended interventions and investigations was obtained from 
each patient before surgery.

\subsection{Surgical Procedures}

All procedures were performed via a midline transperitoneal approach except for one patient who underwent supraceliac aortic clamping via a retroperitoneal approach with the Stoney incision. We mobilized the left renal vein to access the proximal aortic neck, but did not divide it. Preserving renal blood flow as much as possible, we selected the proximal clamping level based on the extension of the aneurysm judging from the preoperative computed tomography and intraoperative findings. One or both renal arteries were blocked externally prior to the aortic cross-clamping as much as possible to prevent renal artery embolism. After incising the aneurysm, we debrided the protruding atherosclerotic aortic plaque near the suture line and washed thoroughly, and then, released the blockage of the renal arteries and cannulated the renal artery ostia with a balloon-tipped catheter. We perfused the kidneys with cold $\left(4^{\circ} \mathrm{C}\right)$ Ringer's solution, which consisted of $500 \mathrm{ml}$ of lactated Ringer's solution, $7 \mathrm{ml}$ of $7 \%$ sodium bicarbonate solution, $300 \mathrm{mg}$ of methylprednisolone, and 2000 units of heparin sodium, for 39 patients (72\%) (perfusion group). However, 15 patients did not receive the renal perfusion because of the difficulty of cannulation or the surgeon's preference (non-perfusion group). In the perfusion group, perfusion was performed at the rate of $250 \mathrm{~mL} / \mathrm{min}$ of solution per kidney before 2011. From 2011, perfusion was performed at a rate of $250 \mathrm{ml}$ of solution per kidney for 5 min. After completing the proximal anastomosis, the graft and proximal aorta were flushed by the temporary removal of the aortic clamp. The graft was then cross clamped below the anastomosis, and the aortic clamp at the aorta was removed to restore the renal blood flow while the distal anastomosis was completed. Forty-eight patients underwent repair with proximal anastomosis just below the renal arteries; 6 patients (11\%) with PAAA required renal artery revascularization. The reasons for surgery were ruptured aneurysm in one patient (2\%), dilated aneurysm with a maximum diameter of $>50 \mathrm{~mm}$ or rapidly enlarging aneurysm in 42 patients (78\%), and saccular aortic aneurysm which seemed prone to rupture in 11 patients $(20 \%)$.

\subsection{Perioperative Management}

We tried to maintain renal function with adequate infusion management and blood pressure control. However, if the patient's renal function declined to oliguria, we introduced continuous renal replacement therapy.

\subsection{Statistical Analysis}

The results are expressed as means \pm standard deviations. Statistical analyses were performed using the t-test or Wilcoxon signed-rank test for continuous variables and the Chi-square test for categorical variables. Patient characteristics, operative details, and postoperative outcome data were obtained from the clini- 
cal records and were compared between the perfusion group and non-perfusion group. The preoperative, postoperative, and discharge serum creatinine level ( $\mathrm{Cr}$ ), and percentage of patients with $\mathrm{Cr}>2 \mathrm{mg} / \mathrm{dL}$, and rate of change of $\mathrm{Cr}$ [postoperative $\mathrm{Cr}$ /preoperative $\mathrm{Cr} \times 100(\%)$ and discharge $\mathrm{Cr} /$ preoperative $\mathrm{Cr} \times 100(\%)$, respectively] were used to evaluate renal function and were compared between the groups. The correlation between the rate of change of postoperative $\mathrm{Cr}$ and renal ischemia time was verified using Pearson's correlation test. A value of $\mathrm{p}<$ 0.05 was considered statistically significant.

\section{Results}

\subsection{Patient Characteristics and Preoperative Renal Function}

Table 1 summarizes the preoperative characteristics of patients who underwent P/JAAAs repair. Table 2 shows the preoperative Cr. The mean age was $72 \pm 7$ (range 54 - 85) years, and 49 patients (91\%) were men. One patient (2\%) had ruptured AAA. Six patients (11\%) had PAAA. The mean diameter of the aortic aneurysm was $55 \pm 10 \mathrm{~mm}$. In terms of disease etiology, 53 (98\%) patients had atherosclerotic aneurysm and only one patient (2\%) had inflammatory aortic aneurysm. Patients with dissecting aneurysm or infected aneurysm were unnoted in this study. Thirty-two patients (59\%) had chronic kidney disease (CKD) of stage 3 and over (stage 3: 26, stage 4: 5, and stage 5: 1, respectively) [11]. Preoperative Cr was $1.16 \pm 0.53$ (range $0.50-3.47$ ) $\mathrm{mg} / \mathrm{dL}$ and 4 patients (7\%) had $\mathrm{Cr}>2 \mathrm{mg} / \mathrm{dL}$.

There were no significant differences in age, sex, and comorbidities between the perfusion and non-perfusion groups. The perfusion group had a non-significantly lower preoperative $\mathrm{Cr}$ than the non-perfusion group [1.08 \pm 0.42 vs. $1.35 \pm 0.71$ $\mathrm{mg} / \mathrm{dL}(\mathrm{p}=0.09)]$.

Table 1. Preoperative characteristics.

\begin{tabular}{|c|c|c|c|c|}
\hline Variable & $\begin{array}{c}\text { All } \\
(\mathrm{n}=54)\end{array}$ & $\begin{array}{l}\text { Perfusion } \\
(\mathrm{n}=39)\end{array}$ & $\begin{array}{l}\text { No perfusion } \\
\quad(\mathrm{n}=15)\end{array}$ & $\mathrm{P}$ \\
\hline Age, years & $72 \pm 7$ & $72 \pm 7$ & $73 \pm 9$ & 0.6 \\
\hline Male sex, n (\%) & 49 (91\%) & $36(92 \%)$ & $13(87 \%)$ & 0.9 \\
\hline Hypertension, n (\%) & $45(83 \%)$ & $32(82 \%)$ & $13(87 \%)$ & 0.9 \\
\hline Diabetes mellitus, n (\%) & $7(13 \%)$ & $3(8 \%)$ & $4(27 \%)$ & 0.3 \\
\hline Coronary artery disease, n (\%) & $21(39 \%)$ & $16(41 \%)$ & $5(33 \%)$ & 0.9 \\
\hline Peripheral artery disease, $\mathrm{n}(\%)$ & $3(6 \%)$ & $1(3 \%)$ & $2(13 \%)$ & 0.5 \\
\hline AAA size, $\mathrm{mm}$ & $55 \pm 10$ & $54 \pm 8$ & $58 \pm 13$ & 0.2 \\
\hline Saccular AAA, n (\%) & $11(20 \%)$ & $6(15 \%)$ & $5(33 \%)$ & 0.5 \\
\hline Ruptured AAA, n (\%) & $1(2 \%)$ & 0 & $1(7 \%)$ & 0.4 \\
\hline Pararenal AAA, n (\%) & $6(11 \%)$ & $6(15 \%)$ & 0 & 0.1 \\
\hline CKD stage $\geq 3$ & $32(59 \%)$ & $22(56 \%)$ & $10(67 \%)$ & 0.9 \\
\hline
\end{tabular}

AAA: abdominal aortic aneurysm; CKD: chronic kidney disease. 


\subsection{Operative Data}

Table 3 provides a summary of the operative data. The proximal aortic clamping level was the supraceliac artery in 1 patient (2\%), suprarenal arteries in 30 patients (56\%), and inter-renal arteries in 23 patients (42\%). In the perfusion group, 15 patients (38\%) received bilateral perfusion and 24 patients (62\%) received unilateral perfusion; those whose aortic clamp was above the renal arteries did not always receive bilateral perfusion. Six patients in the perfusion group also required revascularization of the renal artery; two of them underwent bilateral revascularization. The renal ischemia time was $49 \pm 19$ (range 30 - 106) min; there was no significant difference between the perfusion and non-perfusion groups ( 49 \pm 21 vs. $47 \pm 11$ min; $\mathrm{p}=0.8$ ).

Table 2. Changes in renal function.

\begin{tabular}{|c|c|c|c|c|}
\hline Variable & $\begin{array}{c}\text { All } \\
(\mathrm{n}=54)\end{array}$ & $\begin{array}{c}\text { Perfusion } \\
(\mathrm{n}=39)\end{array}$ & $\begin{array}{l}\text { No perfusion } \\
\quad(\mathrm{n}=15)\end{array}$ & $\mathrm{P}$ \\
\hline \multicolumn{5}{|l|}{ Preoperative } \\
\hline $\mathrm{Cr}(\mathrm{mg} / \mathrm{dL})$ & $1.16 \pm 0.53$ & $1.08 \pm 0.42$ & $1.35 \pm 0.71$ & 0.09 \\
\hline $\mathrm{Cr}>2 \mathrm{mg} / \mathrm{dL}, \mathrm{n}(\%)$ & $4(7 \%)$ & $2(5 \%)$ & $2(13 \%)$ & 0.8 \\
\hline \multicolumn{5}{|l|}{ Postoperative } \\
\hline $\mathrm{Cr}(\mathrm{mg} / \mathrm{dL})$ & $1.69 \pm 0.96^{*}$ & $1.48 \pm 0.76^{*}$ & $2.23 \pm 1.21^{*}$ & $<0.01$ \\
\hline $\mathrm{Cr}>2 \mathrm{mg} / \mathrm{dL}, \mathrm{n}(\%)$ & $12(22 \%)$ & $5(13 \%)$ & $7(47 \%)$ & $<0.01$ \\
\hline Rate of change of $\mathrm{Cr}(\%)^{\#}$ & $152 \pm 71$ & $140 \pm 53$ & $183 \pm 101$ & 0.04 \\
\hline \multicolumn{5}{|l|}{ Discharge } \\
\hline $\mathrm{Cr}(\mathrm{mg} / \mathrm{dL})$ & $1.14 \pm 0.56$ & $1.05 \pm 0.44$ & $1.38 \pm 0.75$ & 0.04 \\
\hline $\mathrm{Cr}>2 \mathrm{mg} / \mathrm{dL}, \mathrm{n}(\%)$ & $5(9 \%)$ & $3(8 \%)$ & $2(13 \%)$ & 0.5 \\
\hline Rate of change of $\mathrm{Cr}^{\# \#}$ & $100 \pm 21$ & $98 \pm 21$ & $105 \pm 21$ & 0.3 \\
\hline
\end{tabular}

Cr: serum creatinine level. ${ }^{*}$ p value $<0.05$ versus preoperative. ${ }^{*}$ postoperative $\mathrm{Cr} /$ preoperative $\mathrm{Cr} \times 100$ (\%). ${ }^{\# \#}$ discharge $\mathrm{Cr} /$ preoperative $\mathrm{Cr} \times 100$ (\%).

Table 3. Operative data.

\begin{tabular}{ccccc}
\hline Variable & $\begin{array}{c}\text { All } \\
(\mathrm{n}=54)\end{array}$ & $\begin{array}{c}\text { Perfusion } \\
(\mathrm{n}=39)\end{array}$ & $\begin{array}{c}\text { No perfusion } \\
(\mathrm{n}=15)\end{array}$ & $\mathrm{P}$ \\
\hline Aorta clamping level & & & & \\
Supraceliac artery, n (\%) & $1(2 \%)$ & $1(3 \%)$ & 0 & 0.9 \\
$\begin{array}{c}\text { Suprarenal arteries, n (\%) } \\
\text { Inter-renal arteries, n (\%) }\end{array}$ & $30(56 \%)$ & $23(59 \%)$ & $7(47 \%)$ & 0.9 \\
Renal perfusion & $23(42 \%)$ & $15(38 \%)$ & $8(53 \%)$ & 0.8 \\
bilateral perfusion, n (\%) & $15(28 \%)$ & $15(38 \%)$ & - & - \\
unilateral perfusion, n (\%) & $24(44 \%)$ & $24(62 \%)$ & - & 0.5 \\
Reconstruction of renal artery, n (\%) & $6(11 \%)$ & $6(15 \%)$ & 0 & 0.8 \\
\hline Renal ischemia time (min) & $49 \pm 19$ & $49 \pm 21$ & $47 \pm 11$ & \\
\hline
\end{tabular}




\subsection{Change in Postoperative Renal Function and Clinical Outcome}

The changes in $\mathrm{Cr}$ are presented in Table 2. One patient in the non-perfusion group needed continuous renal replacement therapy. Postoperative $\mathrm{Cr}$ significantly worsened in both groups $[1.08 \pm 0.42$ to $1.48 \pm 0.76 \mathrm{mg} / \mathrm{dL}(\mathrm{p}<0.01)$, perfusion group; $1.35 \pm 0.71$ to $2.23 \pm 1.21 \mathrm{mg} / \mathrm{dL}$ ( $\mathrm{p}<0.01$ ), non-perfusion group]. Figure 1 shows the correlation between the rate of change of postoperative $\mathrm{Cr}$ and renal ischemia time. The more the renal ischemia time was prolonged, the more the rate of change of postoperative $\mathrm{Cr}$ roughly increased in both groups. However, the postoperative $\mathrm{Cr}$ in the perfusion group was significantly lower than that in the non-perfusion group (1.48 \pm 0.76 vs. $2.23 \pm 1.21$ $\mathrm{mg} / \mathrm{dL}, \mathrm{p}<0.01)$. The rate of change of postoperative $\mathrm{Cr}$ and percentage of patients with postoperative $\mathrm{Cr}>2 \mathrm{mg} / \mathrm{dL}$ were also significantly lower in the perfusion group than in the non-perfusion group [140 \pm 53 vs. $183 \pm 101 \%(\mathrm{p}=$ $0.04)$ and $5(13 \%)$ vs. $7(47 \%)(\mathrm{p}<0.01)$, respectively].

At discharge, there was still a significant difference in $\mathrm{Cr}$ between both groups $(1.05 \pm 0.44$ vs. $1.38 \pm 0.75 \mathrm{mg} / \mathrm{dL}, \mathrm{p}=0.04)$. However, there were no significant differences in the rate of change of $\mathrm{Cr}$ and percentage of patients with postoperative $\mathrm{Cr}>2 \mathrm{mg} / \mathrm{dL}$ between groups [98 \pm 21 vs. $105 \pm 21 \%(\mathrm{p}=0.3)$ and $3(8 \%)$ vs. $2(13 \%)(\mathrm{p}=0.5)$, respectively]. There was also no significant difference in the postoperative length of stay between the groups (19 \pm 8 vs. $22 \pm 8$ days, $p=$ 0.2 ). All patients left the hospital without incidents and none needed permanent hemodialysis.

\section{Discussion}

In this study, although there was no significant difference with respect to renal ischemia time, the perfusion group had a significantly lower postoperative $\mathrm{Cr}$ change rate, and fewer patients with postoperative $\mathrm{Cr}>2 \mathrm{mg} / \mathrm{dL}$ compared to
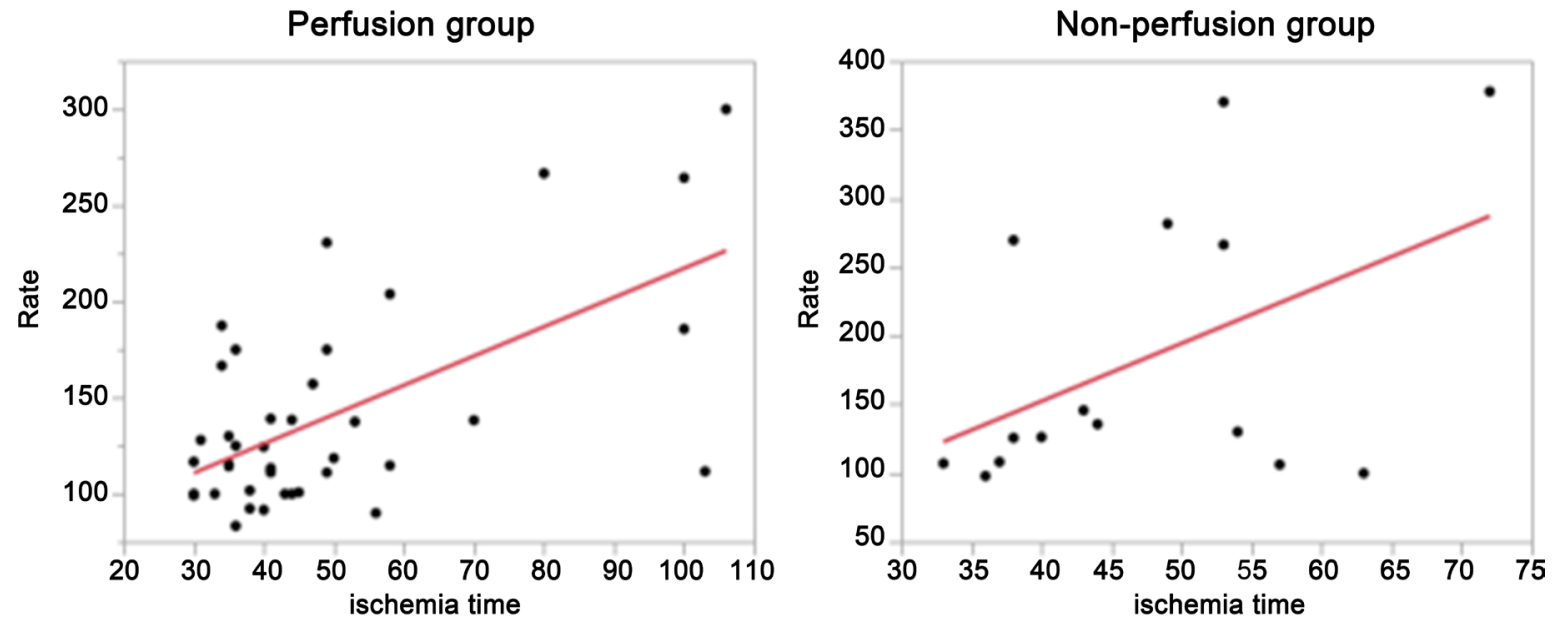

Figure 1. Correlation between the rate of change of postoperative $\mathrm{Cr}$ and renal ischemia time. The rate of change of postoperative $\mathrm{Cr}$ in the perfusion group showed a significant positive correlation with renal ischemia time $\left(\mathrm{R}^{2}=0.37, \mathrm{p}\right.$ $<0.04)$. The rate of change of postoperative $\mathrm{Cr}$ in the non-perfusion group also showed a positive but non-significant correlation with renal ischemia time $\left(\mathrm{R}^{2}=0.22, \mathrm{p}=0.07\right)$. 
the non-perfusion group. Thus, renal perfusion with cold Ringer's solution contributed to preserved postoperative renal function.

Kidney hypothermia may help to improve the surgical outcome of suprarenal aortic clamping for P/JAAA. Renal oxygen consumption is reduced to $40 \%$ when the renal parenchyma is cooled to $30^{\circ} \mathrm{C}$, to $15 \%$ at $20^{\circ} \mathrm{C}$, and to less than $5 \%$ at $10^{\circ} \mathrm{C}[12]$. The permissible renal ischemia time when the renal parenchyma is cooled to $15^{\circ} \mathrm{C}-25^{\circ} \mathrm{C}$ was reported to be about $2 \mathrm{~h}$ [13]. Interestingly, in a study of direct kidney cooling, there was no difference in postoperative renal outcomes among kidneys cooled to $<15^{\circ} \mathrm{C}$ versus kidneys cooled to $15^{\circ} \mathrm{C}-28^{\circ} \mathrm{C}$, suggesting that profound hypothermia is not required to protect renal function [14]. In thoracoabdominal aortic aneurysms repair, the benefits of cold renal perfusion are well established [14]. However, there is no high-level evidence showing that intraoperative cold renal perfusion can prevent postoperative renal dysfunction in patients with P/JAAA [8]. Moreover, cannulation into the renal artery ostia with a catheter could cause renal artery embolization and dissection [6], the risk of hypothermia is the risk of systemic cooling, worsening tissue oxygenation by shifting the oxyhemoglobin dissociation curve to the left, and heterogeneous renal cortex cooling due to convection losses to the normothermic surrounding tissues [15].

In the reports using the clamp and saw technique without special renal protection for P/JAAA, the average renal ischemia time was 24 - 37 min [1] [2] [8] [16] [17] [18], and in particular, if the renal ischemia time was less than $30 \mathrm{~min}$, the impact of renal ischemia on renal function was insignificant [1] [8] [17]. In these ways, the renal ischemia time reported in P/JAAA surgery was not very long, and the patients undergoing the clamp and saw technique without special renal protection for P/JAAA would be tolerant to renal ischemia. However, preoperative renal dysfunction [2] [17] [18] and prolonged renal ischemia time for $30 \mathrm{~min}$ or more are considered as risk factors for postoperative deterioration of renal function [1] [7] [8], and the incidence of postoperative renal failure increases 10 times when the renal ischemia time lasts more than 50 min compared to less than $20 \mathrm{~min}$ [18].

The renal ischemia time in this study was about $50 \mathrm{~min}$, which seems longer than previously reported, including a time of $24-37 \mathrm{~min}$ using the clamp and saw technique [1] [2] [8] [16] [17] [18] and 37 - 46 min using renal perfusion [6] [7] [19]. In particular, the causes of the prolonged renal ischemia time in our renal perfusion group might include perfusion of the renal artery with a solution and cases requiring renal artery reconstruction. Moreover, our proficiency level in surgery for P/JAAA might have had the most profound effect on the prolongation of the renal ischemia time. However, as the frequency of EVAR increases, open repair may be indicated more for cases with notable difficulty like P/JAAA; the renal ischemia time may be prolonged in such cases. In order to safely cope with such cases, we believe that it was meaningful that our study revealed the importance of cold renal perfusion. 
On the other hand, the $\mathrm{Cr}$ change rate in the perfusion group showed a positive correlation with the renal ischemia time in this study. As a result, it took some time for the postoperative renal function to return to the preoperative value, which might be related to the fact that there was no difference with respect to the postoperative length of stay between the renal perfusion and non-perfusion groups. In this study, we perfused the kidney at the rate of $250 \mathrm{~mL} / \mathrm{min}$ per kidney or at $250 \mathrm{ml} / 5 \mathrm{~min}$ per kidney. Although there is no established rule for the cold renal perfusion method, the amount of renal perfusion in this study was less than that reported in other studies [5] [6] [15] [19]. Judging from the fact that the $\mathrm{Cr}$ change rate in the perfusion group showed a positive correlation with renal ischemia time, our procedure might not be sufficient to prevent postoperative renal function deterioration [6]. We perfused the kidney with a smaller amount of cold Ringer's solution compared to the previous reports considering the risk of systemic cooling and associated complications. However, the influence of cold renal perfusion on the deep body temperature seems to be small [6] [15]. Thus, we would like to reconsider our method including the injection volume and speed hereafter.

Other factors affecting postoperative renal function may include the proximal aortic clamp level [2] [8] and the presence or absence of division of the left renal vein [8] [17]. Regarding the proximal aortic clamp level, supravisceral aortic clamping above the celiac artery or superior mesenteric artery has been reported as a risk factor for postoperative renal function deterioration [2] [20]. Myers et al. showed that nitric oxide is important in maintaining renal cortical and medullary blood flow and function. In addition to the renal ischemia-reperfusion injury caused by renal blood flow interruption, superior mesenteric artery blood flow interruption induces mesenteric ischemia-reperfusion. This reperfusion further results in the generation of oxygen-derived free radicals that contribute to decreased renal cortical and medullary nitric oxide synthesis. They also suggested that maintaining visceral blood flow might be helpful in developing strategies to minimize renal ischemia-reperfusion injury [20]. In the present study, regardless of the presence or absence of cold renal perfusion, we avoided supraceliac aortic clamping as much as possible, and in possible cases, we clamped the aorta at the level between renal arteries to preserve renal blood flow as much as possible [2]. Moreover, we tried to prevent renal artery embolization by the external blockage of the renal arteries prior to the aortic cross-clamping and by releasing the blockage after the debridement of the protruding atherosclerotic aortic plaque and irrigation. Moreover, did not divide the left renal vein. All these factors might have contributed to preserving renal function.

In this study, even in the non-perfusion group, the $\mathrm{Cr}$ value returned to the preoperative value at discharge; however, the postoperative $\mathrm{Cr}$ was significantly worse than that of the perfusion group. As many of the patients in this study had CKD of stage 3 or more, and were at a long-term risk of renal impairment [17], the more elderly people with renal dysfunction will be subject to the open repair 
for P/JAAA in future. Since intraoperative transient ischemia stress could enhance this deterioration, cold renal perfusion may be recommended for P/JAAA, especially in institutions with low proficiency in surgery for P/JAAA.

Cold blood perfusion according to thoracoabdominal aortic surgery [15] and venous blood perfusion from the internal jugular vein through a roller pump [7] were reported to be alternatives for perfusing the kidney, with good renal protective effects. However, cold renal perfusion using Ringer's solution may be simpler and easier to perform.

Both fenestrated and chimney techniques using EVAR are attractive options for P/JAAA treatment, with encouraging early and mid-term outcomes; however, compared with open repair, there are some problems regarding higher rates of secondary reintervention and renal impairment during follow-up [21] [22]. Therefore, individualized decision-making regarding the choice of procedure and the preferences of the patient should be considered.

\section{Limitation}

The limitations of this study include its retrospective design and the small number of patients. This study was not a complete control study because the non-perfusion group was not randomly selected. Only the patients whose proximal aortic clamping was placed above the bilateral renal arteries with or without bilateral renal perfusion should have been included in this study to clarify the influence of cold renal perfusion on renal function and clinical outcomes. However, this study included various combinations of proximal aortic clamping levels, the presence or absence of unilateral or bilateral renal ischemia, and the presence or absence of unilateral or bilateral renal perfusion. Although the long-term influence of the presence or absence of cold renal perfusion on renal function is interesting, this issue was not considered in this study.

\section{Conclusion}

Renal artery perfusion with cold Ringer's solution clearly reduced the deterioration of postoperative renal function compared to non-renal perfusion. Thus, renal artery perfusion with cold Ringer's solution is a practical means of renal protection in P/JAAA surgery where prolonged renal ischemia time is expected.

\section{Acknowledgements}

We thank Editage (https://www.editage.jp) for the English language editing.

\section{Conflicts of Interest}

The authors declare no conflicts of interest regarding the publication of this paper.

\section{References}

[1] Ferrante, A.M., Moscato, U., Colacchio, E.C., et al. (2016) Results after Elective Open 
Repair of Pararenal Abdominal Aortic Aneurysms. Journal of Vascular Surgery, 63, 1443-1450. https://doi.org/10.1016/j.jvs.2015.12.034

[2] Sarac, T.P., Clair, D.G., Hertzer, N.R., et al. (2002) Contemporary Results of Juxtarenal Aneurysm Repair. Journal of Vascular Surgery, 36, 1104-1111.

https://doi.org/10.1067/mva.2002.129638

[3] West, C.A., Noel, A.A., Bower, T.C., et al. (2006) Factors Affecting Outcomes of Open Surgical Repair of Pararenal Aortic Aneurysms: A 10-Year Experience. Journal of Vascular Surgery, 43, 921-928. https://doi.org/10.1016/j.jvs.2006.01.018

[4] Faggioli, G., Stella, A., Freyrie, A., et al. (1998) Early and Long-Term Results in the Surgical Treatment of Juxtarenal and Pararenal Aortic Aneurysms. European Journal of Vascular and Endovascular Surgery, 15, 205-211. https://doi.org/10.1016/S1078-5884(98)80177-9

[5] Knott, A.W., Kalra, M., Duncan, A.A., et al. (2008) Open Repair of Juxtarenal Aortic Aneurysms (JAA) Remains a Safe Option in the Era of Fenestrated Endografts. Journal of Vascular Surgery, 47, 695-701. https://doi.org/10.1016/j.jvs.2007.12.007

[6] Yeung, K.K., Jongkind, V., Coveliers, H.M., et al. (2008) Routine Continuous Cold Perfusion of the Kidneys during Elective Juxtarenal Aortic Aneurysm Repair. European Journal of Vascular and Endovascular Surgery, 35, 446-451. https://doi.org/10.1016/j.ejvs.2007.11.022

[7] Pichlmaier, M., Hoy, L., Wilhelmi, M., et al. (2008) Renal Perfusion with Venous Blood Extends the Permissible Suprarenal Clamp Time in Abdominal Aortic Surgery. Journal of Vascular Surgery, 47, 1134-1140.

https://doi.org/10.1016/j.jvs.2008.01.020

[8] Dubois, L., Durant, C., Harrington, D.M., et al. (2013) Technical Factors Are Strongest Predictors of Postoperative Renal Dysfunction after Open Transperitoneal Juxtarenal Abdominal Aortic Aneurysm Repair. Journal of Vascular Surgery, 57, 648-654. https://doi.org/10.1016/j.jvs.2012.09.043

[9] Jongkind, V., Yeung, K.K., Akkersdijk, G.J., et al. (2010) Juxtarenal Aortic Aneurysm Repair. Journal of Vascular Surgery, 52, 760-767. https://doi.org/10.1016/j.jvs.2010.01.049

[10] Chiesa, R., Tshomba, Y., Mascia, D., et al. (2013) Open Repair for Juxtarenal Aortic Aneurysms. The Journal of Cardiovascular Surgery (Torino), 54, 35-45.

[11] National Kidney Foundation (2002) K/DOQI Clinical Practice Guidelines for Chronic Kidney Disease: Evaluation, Classification, and Stratification. American Journal of Kidney Diseases, 39, S1-S266.

[12] Semb, G., Krog, J. and Johansen, K. (1960) Renal Metabolism and Blood Flow during Local Hypothermia, Studied by Means of Renal Perfusion in Situ. Acta Chirurgica Scandinavica Supplementum, 253, 196-202.

[13] Levy, M.N. (1959) Oxygen Consumption and Blood Flow in the Hypothermic, Perfused Kidney. American Journal of Physiology, 197, 1111-1114. https://doi.org/10.1152/ajplegacy.1959.197.5.1111

[14] Lemaire, S.A., Jones, M.M., Conklin, L.D., et al. (2009) Randomized Comparison of Cold Blood and Cold Crystalloid Renal Perfusion for Renal Protection during Thoracoabdominal Aortic Aneurysm Repair. Journal of Vascular Surgery, 49, 11-19. https://doi.org/10.1016/j.jvs.2008.08.048

[15] Black, J.H. (2013) Renal Protection in Juxtarenal and Suprarenal Aortic Aneurysm Surgery. Seminars in Vascular Surgery, 26, 193-198.

https://doi.org/10.1053/j.semvascsurg.2014.06.005 
[16] Hoshina, K., Nemoto, M., Shigematsu, K., et al. (2014) Effect of Suprarenal Aortic Cross-Clamping. Circulation Journal, 78, 2219-2224. https://doi.org/10.1253/circj.CJ-14-0384

[17] Sugimoto, M., Takahashi, N., Niimi, K., et al. (2018) Long-Term Fate of Renal Function after Open Surgery for Juxtarenal and Pararenal Aortic Aneurysm. Journal of Vascular Surgery, 67, 1042-1050. https://doi.org/10.1016/j.jvs.2017.07.121

[18] Wahlberg, E., Dimuzio, P.J. and Stoney, R.J. (2002) Aortic Clamping during Elective Operations for Infrarenal Disease: The Influence of Clamping Time on Renal Function. Journal of Vascular Surgery, 36, 13-18. https://doi.org/10.1067/mva.2002.123679

[19] Allen, B.T., Anderson, C.B., Rubin, B.G., et al. (1993) Preservation of Renal Function in Juxtarenal and Suprarenal Abdominal Aortic Aneurysm Repair. Journal of Vascular Surgery, 17, 948-959. https://doi.org/10.1016/0741-5214(93)90045-N

[20] Myers, S.I., Wang, L. and Myers, D.J. (2007) Loss of Renal Function and Microvascular Blood Flow after Suprarenal Aortic Clamping and Reperfusion (SPACR) above the Superior Mesenteric Artery Is Greatly Augmented Compared with SPACR above the Renal Arteries. Journal of Vascular Surgery, 45, 357-366. https://doi.org/10.1016/j.jvs.2006.10.045

[21] Rao, R., Lane, T.R., Franklin, I.J., et al. (2015) Open Repair versus Fenestrated Endovascular Aneurysm Repair of Juxtarenal Aneurysms. Journal of Vascular Surgery, 61, 242-255. https://doi.org/10.1016/j.jvs.2014.08.068

[22] Shahverdyan, R., Majd, M.P., Thul, R., et al. (2015) F-EVAR Does Not Impair Renal Function More than Open Surgery for Juxtarenal Aortic Aneurysms: Single Centre Results. European Journal of Vascular and Endovascular Surgery, 50, 432-441. https://doi.org/10.1016/j.ejvs.2015.04.028 